\title{
Do método no ensino do direito civil
}

\author{
Jorge Americano
}

Preleção inaugural á abertura das aulas em 1934.

\section{DISTRIBUIÇÃO DA MATÉRIA}

A matéria do direito civil, que o nosso Codigo divide, de acôrdo com a doutrina, em Parte Geral e Parte Especial, distribúe-se por ambas segundo um critério de rigorosa sucessão de todas as suas divisões: Se, para constatar a existência da relação juridica, há sempre mistér um sujeito, que é o titular do direito, um objeto, que é o bem material ou imaterial, e uma relação de direito, que subordina o bem ao sujeito, aí temos, lógicamente justificado o Código na divisão que faz, na parte geral, Das Pessoas, Dos Bens e Dos Fatos Juridicos.

E logo que se particulariza, torna-se necessário estudar o homem nas suas relações personalissimas (Familia); em seguida, as Coisas, na sua pertinência ao sujeito; depois os bens consistentes em prestações de uns homens para com os outros homens (Obrigações), e finalmente, as relações decorrentes da extinção da personalidade humana pela morte (Sucessões).

Mas, se, com ligeiras variantes, os sistemas modernos obedecem a esta classificação, surge, na questão ao ensino, a seguinte dificuldade: 
Considerada a matéria em seu conjunto - parte geral tripartida, formando um todo de extensão eqüivalente a cada uma das quatro divisões da parte especial, como se devem distribuir eqüitativamente por quatro anos do curso estas cinco partes, sem acumular um dos anos, nem inverter a ordem lógica das matérias?

O direito civil era antes distribuido por tres anos de curso. Dado o aumento de um ano nesta disciplina, os sucessivos decretos de promoção, a interrupção do curso pela guerra constitucionalista, a danosa condensação de todo o curso jurídico em quatro anos, últimamente feita a título de exceção, que aliás já se verifica como regra, durante anos sucessivos, ainda não permitiram encarar a rigor a distribuição da matéria de direito civil, controlando-a pelos resultados práticos obtidos em turmas que sigam ordenadamente os estudos.

Não havendo divisor comum entre o número de quatro anos do curso de direito civil, e as cinco partes em que se póde dividir a matéria - parte geral, familia, coisas, obrigações, sucessões - nenhuma solução aritmética se póde dar, que satisfaça ás necessidades do ensino.

A matéria que abordo é, pois, sujeita á verificação da subseqüente experiência. Parece-me que as afinidades entre a Teoria geral do Direito Civil, e a Teoria Geral das Obrigações, e a extensão relativamente pequena da primeira, autorizam junta-las ambas no primeiro dos quatro anos do Curso de Direito Civil.

Tiro aqui uma consideração dos estudos correlatos de Direito Comercial, de vez que nenhuma disciplina póde ser considerada sem o desenvolvimento paralelo do curso das demais. Quanto mais cedo fizer o estudo do Direito das Obrigações, tanto na parte geral, como na dos contratos, mais apto estará o aluno á receptividade do ensino de Direito Comercial, ao passo que o conhecimento do Direito das Coisas ainda não é indispensavel ao estudante do primeiro ano de Direito Comercial. 
Lógo surge, porém, a necessidade de desenvolver, no ano seguinte, os Contratos, que são a parte especial das Obrigações, muito mais extensa que a parte geral. E como esta matéria das obrigações exige a cada passo mais desenvolvimento, dada a maior extensão que a economia toma, dia por dia, na nossa vida, produzindo nas Obrigações e Contratos a maior aceleração evolutiva do Direito Civil, convem que o segundo ano do Direito Civil se ocupe inteira e sómente dos Contratos, dando relêvo aos principios gerais, na sua aplicação a cada Instituto. Tambem persiste o motivo da correlação com o Direito Comercial.

Restam, para os dois anos seguintes, o Direito das Coisas, o Direito de Familia e o das Sucessões. A extensão dos seus estudos não é em tal modo diversa que o desenvolvimento do Direito das Coisas ocupe o dobro do tempo de cada uma das outras. Nem há meio de dividir uma destas, para distribui-la por dois anos, de modo a preencher o Curso.

Entretanto, algumas considerações justificam que o Direito das Coisas venha sózinho no terceiro ano de Direito Civil, e que se acumulem no último ano o Direito de Familia e o das Sucessões.

E que no direito das Coisas se encontra, inicialmente, a dificilima teoria da Posse, que ocupa extenso número de aulas. Encontram-se os direitos reais de garantia, que exigem estudo mais desenvolvido, quanto mais se aperfeiçoam e se multiplicam as relações do crédito. E se encontram os direitos intelectuais, que merecem acurado estudo.

Dir-se-á, em contraposição, que o Direito de Familia tem irrecusavel importância, bem como o das Sucessões, justamente no momento da humanidade em que o primeiro sofre a ameaça de graves reformas e o segundo corre o risco de cair por terra. E que para opinar e decidir nesta contingência, deve o jurista conhecê-los a fundo.

Certo que sim. Mas é preciso considerar que a questão não está principalmente no terreno juridico. $O$ que se ataca é a sua base social e biológica. A organização da familia é estudada sob aspectos novos, á luz da biologia, no exame 
de toda a questão sexual, da psicologia conjugal, da psicologia infantil, da pedagogia, das relações entre os fiilhos e os pais, da educação do Estado, etc., etc. E o Direito das Sucessões recebe os golpes que lhe vibram os adeptos das novas escolas econômicas. Os maiores debates não estão dentro do terreno jurídico, mas fóra dele, e, portanto, ao professor de Direito Civil incumbe, principalmente, expor os princípios e esboçar as críticas, remetendo os alunos aos estudos de sociologia mais aptos a desenvolvimento neste terreno.

Cumpre atender ainda que, chegado ao quarto ano de Direito Civil, o aluno tem maior ginástica intelectual e maior bagagem de estudos, tem maior receptividade, portanto. Assim, ainda que estas matérias da familia e sucessão sejam extensas, a receptividade do aluno supre a brevidade do curso.

Cumpre ainda rebater a objeção de ser absurdo deixar o Direito de Familia para o fim, quando o mais elementar raciocinio coloca as relações de familia antes das demais. Isso, porém não autoriza a precipuidade da sua colocação didática, porque a organização da familia, como fato humano, é conhecida por todos, indenpendentemente de estudos jurídicos. E nada impõe o seu estudo anterior ao das Obrigações, ao das Coisas, por que êstes estudos não se entrelaçam ao Direito de Familia, senão na matéria das Sucessões. Desta sorte, desde que o Direito das Sucessões venha após o de Familia, êste póde vir após o das Obrigações e o das Coisas, sem o mínimo dano para o estudo.

\section{O ALUNO}

Feitas estas considerações quanto á distribuição da matéria, examinemos, por um instante, o aluno. Conforme o programa vigente, principia o curso de Direito Civil no $2 .^{\circ}$ ano do Curso Jurídico. Segundo o programa proposto e dependente de aprovação, deverá principiar no primeiro ano.

Se continuar como está, temos que considerar o aluno do segundo ano. Já terá recebido as breves noções da ca- 
deira de Introdução ao Estudo do Direito, porém nada conhecerá da história e da evolução do Direito, nem do estudo do Direito Romano, cadeira suprimida.

Se se vier a adotar o programa de Direito Civil com inicio no primeiro ano, a situação do aluno ainda é inferior Vem do curso de humanidades, para penetrar em terreno completamente estranho. Salvo a hipótese de conviver em familia com pessôa que exerça a advocacia, a magistratura, o ministério público, não terá a mínima noção da carreira que escolheu. As razões da escolha são incertas e, ordináriamente, entra menos em conta o que se pode chamar uma vocação decidida, prevalecendo o mais das vezes toda a especie de razões sem influência determinante na capacidade do aluno.

Ao recebê-lo a Escola para conhecer matéria totalmente estranha, rarissimos são os tipos, de verdadeira vocação, ou de verdadeira aversão. Quasi todos são passiveis de se aproveitar ou de se perder, segundo a maior ou menor felicidade com que se houverem durante o curso.

Esses correspondem, geralmente, á massa média da população, capaz de absorver o ensino se o professor é bom, incapaz de aproveitar se êle é mau. Num extremo, o grupo dos dificeis, que pouco aparece ás aulas, que não prende a atenção senão quando o assunto é excecionalmente atraente, ou quando o professor desenvolve excecional eloqüência. No outro extremo, o pequeno grupo de vocação, de onde sairão os verdadeiros juristas. É o mais interessante e talvez o mais dificil. Na acuidade do espirito, classifica e julga $\cap$ professor, e póderá vir a descrer da profissão escolhida, se não encontrar alguma correspondência entre a carreira que: ideou, e as aulas que recebe. Mas isso, nós o sabemos, pela observação empírica, não por uma diferenciação rigorosa. O processo diferenciador dos tests reduz-se em eficiência á proporção que sobe o nivel intelectual. Não porque seja inçado teóricamente de erros, mas porque os critérios diferenciadores se multiplicam á proporção que se sobe na escala, de sorte que, sendo possive] distinguir á força de meia duzia de 
tests se uma criança leva desenvolvimento normal, já não o é em um aluno de escola superior, sujeito á infinidade dos fatores educativos, mesológicos, econômicos, que tornam impraticável o método.

Nesse meio vai trabalhar o professor, procurando obter um interêsse igual da parte de todos, procurando fixar a atenção dos desatentos, conduzir a bom termo a grande massa, e não cançar os alunos superiores, cuja inteligência e atenção facilitam compreender logo o que nos demais ainda depende dos processos de elaboração do intelecto.

Nem pode deter-se a provocar a compreensão dos alunos inferiores, porque perderá a dos outros, exhaustos de uma explicação interminavelmente enfadonha, nem pode só ter em vista os melhores, porque sacrificará a grande massa média, aproveitavel.

Tomado por padrão o tipo Imédio, não haverá a perda dos elementos superiores, ao passo que pelo menos alguns dos inferiores poderão igualmente aproveitar-se. Se tomar por padrão o tipo médio, conseguirá aproveitar alguns dos tipos inferiores, ainda capazes, sem cançar e pôr á perda os elementos superiores. Mas só com isso não se obtem dêstes o melhor rendimento. Este se alcança pela diversificação dos tipos de aula.

\section{AS AULAS}

Nenhuma aula supre no alumno o trabalho da meditação. Portanto, em nenhuma aula se lhe ministra o bastante para o curso. Ou lhe despertará o desejo de meditar, ou não será uma aula excelente. A meditação sôbre a matéria do curso dar-se-á gradativamente, na exata proporção do desenvolvimento do senso jurídico do alumno.

\section{A PRELEÇÃO}

O aluno tem que considerar desde logo o Direito como a organização técnica da vida. A dogmática jurídica resul- 
tará, pois, no campo da sociologia, com a teorização necessária, que tem assento no fato humano.

A classificação dos institutos não se lhe afigurará coisa rigida e dogmática, em contraposição aos fenômenos da vida, mas tambem o Direito não se lhe deverá afigurar coisa informe, que se torce e retorce e toma todas as côres.

O espirito de sistema não é espirito de rigidez. A classificação atende a uma necessidade do nosso cerebro, mas não é um conjunto de compartimentos estanques.

$O$ texto particular que eventualmente estiver em exame, será subordinado lógicamente ao instituto a que pertencer, formando aí um todo harmonioso. Examinar-se-ão os princípios determinantes do texto particular, diante dos princípios orientadores do instituto. Por sua vez, cada instituto será estudado em seus principios dominantes, coordenados com os outros institutos de direito.

Cada instituição se entrelaça com as demais, e o exame conjunto denuncia os princípios dominantes na legislação em geral.

Cada instituição se diferencia das demais, por traços peculiares, e a diferenciação rigorosa ativa nos alunos as qualidades críticas, e o espírito lógico.

O Direito Civil será examinado no que tem de carateristico distintivo, bem como na sua entrosagem com as demais disciplinas que compõem o direito em geral.

E' perfeitamente explicavel a supressão da cadeira de Direito Romano, como disciplina autônoma, pois a história do direito não póde ser estudada somente em relação a determinado povo. Cumpre estudar, no Direito Civil, o Direito Romano como fonte, e como um dos dados históricos da sua evolução. A supressão do Direito Comparado, como cadeira autônoma no curso juridico, e bem assim a da cadeira de Filosofia, sugerem o caminho a seguir no ensino do Direito Civil.

Verificar a marcha das instituições no tempo, pelo estudo da história do direito, e ao mesmo passo estudar a variação das instituições dentro de uma mesma época, nos diversos povos, pelo estudo do direito comparado, são ele- 
mentos indispensaveis a quem queira fazer ciência do direito, e não simples empirismo jurídico.

A concatenação do Direito no quadro geral da sociologia, afinal, por meio da filosofia do Direito, evidenciando as influências que sôbre êle exerceram a moral e a religião, de modo a convencer definitivamente que o Direito é uma resultante de conjugação de fatores, e que tambem obedece a leis eqüivalentes ás leis mecânicas do movimento, de sorte a tornar impossivel cortar abruptamente uma tendência em marcha, bem como a gerar inicialmente um movimento em marcha uniforme.

Tudo isto, a que se póde chamar um processo de infiltração do senso filosofico, não se ministra nem se adquire por méra explanação doutrinária. Ministra-se e adquire-se por infiltração lenta, na exposição sintética da doutrina, na crítica analítica da jurisprudência, no exame comparativo das legislações e na manifestação das preferências por algum dos sistemas comparados. Daí a necessidade de filiar cada sistema jurídico á escola filosofica que o gerou, e de fazer-lhe o estudo sob êste aspecto. Esta noção de organismo e de sistema dissipará, afinal, a crença generalizada de que a legislação contém todo o direito vigente.

E quando haja sido feita a completa exposição dos princípios, aí teremos um curso de instituições de direito civil.

\section{A AULA PRATICA}

Mas não basta. Poucos dispõem da faculdade de abstração que permita compreender um instituto pela simples exposição doutrinária. A maior parte exige para compreender as coisas em conjunto, a exemplificação que se expõe em detalhe. Dai a necessidade das aulas práticas, acompanhando o curso teórico.

Durante a minha livre docência tive a oportunidade de ministrar aulas práticas, de acôrdo com o professor da cadeira, e verifiquei como se retem melhor a atenção pondo logo em alvo o exemplo concreto, de modo a fazer com que 
o aluno veja o assunto em todas as suas faces, e não se perca em acompanhar teorias que só se esclarecerão no seu espírito, quando evidenciadas por exemplos de ordem prática.

Figuremos uma hipótese de desquite, tirada da jurisprudência, quando fôr necessario evidenciar a relatividade do conceito da injúria grave. Que melhor exemplo do que êsse da prática forense: A mulher propôs ação de desquite contra o marido, arguindo contra êle, entre outros motivos, o de, por desentendimento, subtrair-lhe a filha de sete meses de idade, em aleitamento materno, e leva-la para lugar ignorado. Em defesa, confessa o marido que levara consigo a criança, e explica tê-lo feito porque pretendia desquitar-se, e não queria deixar a filha com sua mulher; mas nega que o fato de subtrair a filha constitúa injúria por ser ato manifesto de pátrio poder tê-la consigo. Por sua vez considera injúria o fato de chama-lo públicamente a mulher de toxicomaníaco.

A título de curiosidade, informo que a solução foi favoravel á mulher. Por princípio ordinário, que só deixa de prevalecer quando há motivo grave, a mulher tem consigo os filhos de tenra idade, em caso de separação. Logo, o marido que dela se afasta levando consigo a filha em aleitamento, não está procedendo nem na conformidade do princípio legal, nem na conformidade da natureza humana. 0 pátrio poder, quanto á pessoa dos filhos, sintetiza-se na criação, educação e proteção. Subtrair a criança ao aleitamento materno só se justifica, como ato de pátrio poder, quando haja graves motivos que excluam toda a dúvida: razões morais, psicopáticas, ou patológicas. Quanto á reconvenção em que o marido pede compensação de injúrias por ter sido chamado toxicomano, a sentença entendeu que o fato se deu quando a mulher, desesperada, pedia providencias á polícia, para encontrar a criança. E, como expressão desesperada de quem é vítima de dano moral tamanho, atenuase o mal que a imputação pudesse conter, com a consideração de que eram lícitas todas as suposições, inclusive a de 
atribuir ao marido qualquer vício deformante da mentalidade, capaz de reduzir-lhe a sensibilidade moral.

Seja como fôr. Bastou que se expusesse, em matéria de desquite, uma hipótese jurisprudencial, para que a matéria revestisse um aspecto de interêsse que não teria se somente viesse exposta segundo os princípios gerais.

Uma vez lançada a hipótese, já o desquite não é uma regulamentação árida de situações conjugais insustentaveis. É um fato da vida, que é preciso resolver inteligente e humanamente. Nenhuma dificuldade, que desde então surja, deixará de despertar interêsse.

Dois serão os perigos: um, o da excessiva particularização, outro, o da multiplicação dos debates em aula. Mas nem um nem outro pode intimidar. A hipótese carateristica, a hipótese que ilustra, não força necessáriamente á particularização excessiva, antes conduz a maior clarividência quanto á compreensão dos princípios, porque enxerga-se o princípio com mais relevo, quando se o induziu do caso particular, e então estamos aptos a deduzi-lo para aplicar aos casos particulares que surgirem. Mas já é um princípio que tem sua causa nas realidades da vida. E' compreensivo e satisfatório. Resolve situações, não é um preceito abstrato que se alcança nos domínios do puro raciocínio, e se conserva pelo aperfeiçoamento da memória ou pela boa ginástica no manuseio dos indices dos Códigos.

$\mathrm{Na}$ jurisprudência, constantemente invocada, encontrarse-á o conceito vivificador do Direito, e exercitar-se-á a maleabilidade do espírito. A contradição dos advogados e dos juizes, em especies aparentemente idênticas, e a variação dos julgados conforme as instâncias, quanto á mesma demanda em juizo, têm servido a espíritos ligeiros, para desconceituar o Direito.

Diz-se que sempre que alguem acha boas razões de demandar, tambem o seu adversário as acha; e sempre há advogado que espose o patrocínio das pretensões antagônicas; tambem, sempre que se obtem uma consulta com determi- 
nado parecer favoravel, há outro jurisconsulto que consultado pelo adversário, of erece a solução contrária .

Ora, o mais elementar raciocínio manda afastar estas dúvidas, pela consideração de que sempre que procuramos um advogado, procuramos apresentar-lhe bem a nossa pretensão. Seja no sub-conciente, seja no conciente, o certo é que não o procuramos para que êle diga que não temos direito. E esta auto-sugestão influencia toda a exposição feita. Padece do mesmo defeito, ainda que em menor escala, a consulta feita ao jurista, pois muitas vezes ela sugere nos seus proprios termos a solução.

Mas a procura do advogado ou do jurisconsulto é, ordináriamente, a primeira etapa percorrida pelo litigante, na investigação do seu direito subjetivo. Nas sucessivas etapas que forem sendo vencidas, vai-se reduzindo a probabilidade de variação e de erro.

Entretanto, amadores de estatisticas notam que, de 100 decisões proferidas, cerca de 70 por cento encontram tão boas razões para terem sido proferidas em certo sentido, como encontrariam para justifica-las no sentido oposto.

Mas, em rigor, o contingente, por grande que seja, das variações jurisprudenciais, não representa inconsistência de princípios. Um julgado é uma exposição concisa do caso ocorrente, que póde parecer igual a outro julgado, resultando uma aparente incoerência das decisões, enquanto que, na realidade, a variante de detalhes expostos com menos felicidade terá conduzido á diversificação das soluções. Nos casos ocorrentes da vida, não há uma igualdade matemática; logo, ainda que pareçam igualar-se as hipóteses, a solução diversa que a cada uma seja dada, não representa necessáriamente uma incoerência.

Ainda mais:

Os que fazem o confronto das decisões judiciais, não as confrontam só quando constituem soluções definitivas ou casos julgados, mas tambem o fazem em etapas de julgamentos dependentes de reexame e de reforma. E isso, em matéria de estatistica, é erro indesculpavel, é tomar como 
definitiva a solução ainda passivel de reforma, e confrontala com outras já irreformaveis. É dar como iguais coisas desiguais.

Verificado o processo de instrução de uma causa, faz o julgador o seu estudo e profere a decisão. Para êle, julgador, a decisão é exata, pois se assim não fosse, teria proferido diversamente a decisão. Mas o seu processo de investigação e a conseqüente conclusão, que constitúe o julgamento, raro põe termo á demanda. Há o reexame em segunda instância, há os embargos ao acórdão, há a defesa na execução, há até a ação rescisoria do julgado, outros tantos processos de conferir a certeza do primeiro julgado, e retificar os possiveis erros dele constantes.

Devemos supor que se as estatisticas forem feitas no intuito sincero de elucidar, e somente sôbre as decisões irrecorriveis, bem menor será a porcentagem de variação, contigente falivel do erro que acompanha o homem. A infinita variedade dos casos é que conduz á indefinida variação das soluções. Mas, dado o processo de investigação por etapas que se verifica nas hipóteses ocorrentes, o caso que vencer as instâncias e chegar á solução de que não caiba recurso, muito provavelmente chegaria a decisão igual, fossem quem fossem os julgadores.

Ora, considerando estas coisas, que são as que se verificam ordináriamente, é indispensavel que o aluno se habitúe a discernir desde lógo, com a suficiente maleabilidade de inteligência, para não concluir que a vitoria está sempre ao lado de quem expõe bem a sua pretensão e tambem para fugir ao conceito de que o direito pode estar em antagonismo com o proprio direito. 0 exame das hipóteses correntes, na jurisprudência, revela a face que o autor julga favoravel a si, bem como a face que o réu considera dever dar-lhe ganho de causa. Denuncia o primeiro aspecto da investigação do juiz, e os vícios que eventualmente tiver a sua sentença. Revela a multiplicidade das facetas pelas quais a encaram os jurisconsultos, e as feições a que se reduzem, afinal, na segunda instância. 
O aluno que acompanhar a causa e lhe vir a confusão e multiplicidade inicial dos argumentos, a coordenação e o expurgo de muitos deles logo ao estabelecer-se a controvêrsia, a redução desta a determinados pontos, e o efeito que devem êstes produzir na decisão da causa, só não conhecerá e não se aperfeiçoará na mateéria, se realmente não quiser.

\section{AS AULAS DE SEMINÁRIO}

Ainda não basta, porém. Teoria e prática, seguindo correlatamente, revelam as coisas como são. Não servem entretanto á ânsia de aperfeiçoamento. Esta se realiza e se apura nos cursos de investigação, que são os seminários. $\mathrm{Na}$ aula expositiva o estudante aprende os institutos. Nas lições práticas, permanentemente elucidadas com exemplos da jurisprudência, que revela as várias modalidades da vida, ajusta os conceitos ás realidades correntes. Mas no seminário se aperfeiçôa, contribuindo para o progresso científico. Então, aluno e professor são igualmente estudantes, que conjugam esforços. Um mais novo, menos imbuido de classicismo, mais capaz de enxergar diversamente as coisas que são contínuamente olhadas pelo mesmo prisma. Outro, mais capaz de retificar os erros de concepção do primeiro, mais apto a demonstrar, com a soma de conhecimentos anteriores, os vícios e demasias das novidades que seduzem áquele; mas ambos, coordenando-se, examinando, estudando, desenvolvendo-se, atritanto as coisas novas e as velhas, tornando-se mais aptos a contribuir á melhor adaptação do direito á vida. E, principalmente, incutindo o professor no discípulo o amor pelo estudo, preparando o jurista do futuro.

E' mediocre o proveito das aulas ordinárias. A aula prática realiza a indispensavel coordenação entre a realidade e a teoria. E os cursos de seminário servem ás investigações, que criam o verdadeiro amor ao estudo, e geram as capacidades.

O seminário tem, além de outras, a vantagem inestima- 
vel de organizar o método que o estudante praticará em sua vida. Há, na distribuição do trabalho e no processo de conferir os resultados dos seminários, na forma coletiva de examinar as questões, e no debate, o emprêgo dos processos de racionalização de que tanto carecemos.

Todos nós sabemos o que é o trabalho tumultuário de um escritorio de advogado, e a dose de contingente personalissimo do chefe de escritório. Mas tambem sabemos quanta vantagem se tira de uma verdadeira organização de serviço. Não se perdem prazos, não se excedem dilações, não se entregam trabalhos imperfeitos, só pela necessidade de os entregar a tempo.

Ora, o método de seminário, constituindo uma distribuição racional do trabalho para o máximo aproveitamento dos resultados, forma um patrimônio inestimavel a benefício da vida prática. Por outro lado, cria as possibilidades, que entre nós ainda verdadeiramente não realizámos, das obras de colaboração. As afinidades de inteligência, apuradas no seminario, fixam-se para a vida, e o melhor proveito, que é muito, não será para os que assim puderem fazer obra conjunta, mas sim para a coletividade, que por tal modo obterá nessas obras de colaboração resultados que jamais obteria pela soma dos esforços isolados de cada individuo.

Da conjugação dêsses tres tipos de aulas, no Direito Civil, deve o aluno sair conhecedor do sistema legislativo vigente, bem assim prático no manuseio do Código, que fará tanto quanto possivel, provocado pelo professor, toda vez que se referir a um texto expresso. Não basta que o professor o indique, nem que o leia em aula. É necessário que, a cada menção, seja a impressão auditiva acompanhada pela. impressão visual. Que o aluno o leia.

É conveniente, ademais, que a exposição seja acompanhada sem demasias, da citação dos textos, da menção dos nomes e das obras dos juristas.

É vício velho e dificil de extirpar, o de se encherem razões, petições e articulados, de citações longas de autores. Mas nem por ser vício, devem os estudantes deixar de co- 
nhecer autores e obras. A menção adequada do ponto de vista doutrinário de um autor cria convívio espiritual entre êle e os alunos.

\section{OS EXAMES E AS CHAMADAS EM AULA}

Nas grandes turmas que compõem a escola, o conhecimento entre professor e alunos não pode fazer-se pelas chamadas constantes. Dada a assiduidade integral do professor ás aulas, não chega a haver 100 aulas anuais. Ora, não é possivel chamar um aluno por dia. Portanto, em uma turma de 240 alunos, como são as nossas, o professor não chega a chamar uma vez a metade siquer dos alunos. Que o pudesse, não chegaria a conhecer a metade dos alunos, porque uma só vez que se chame á lição, não dá a conhecer o aluno.

A chamada, portanto, não é tanto um meio de conhecer alunos; é, principalmente, um processo de que se serve o professor para ir conferindo sucessivamente as dúvidas que as suas aulas provocam naqueles. É um meio de se corrigir a si próprio, e de se aperfeiçoar. Mas tambem é um meio de se dar a conhecer a seus alunos, de estabelecer a intimidade intelectual e, finalmente, um meio de lhes revelar os métodos de exame oral de que se servirá nas provas finais.

Porque, afinal, é uma situação de perplexidade a do aluno que, cursando as aulas durante todo o ano, sem ter sido chamado, chega, ao exame, considerando o professor um estranho, diante do qual vai submeter-se a um julgamento irrecorrivel.

Não importa que as provas escritas parciais hajam formado para êle uma bagagem de notas, ás vezes indestrutivel mesmo que a prova oral seja má. O que para o bom aluno é indispensavel, o que êle deve desejar, é tirar aproveitamento, e que êste aproveitamento seja autenticado por uma boa nota. A nota não deve resultar de um exame que constitúa para o aluno uma surpreza nos métodos de interrogar por parte do professor. 
Ele deve conhecer os processos de inquirição a que vai ser submetido. As chamadas, pois, seja êle próprio o arguido, ou sejam outros, dão-lhe a conhecer os processos de arguição.

Eis, meus presados e eminentes colegas, eis, senhores alunos, as considerações que julgou util fazer, como preleção inaugural, o mais recente dos Professores da Escola.

Nem foi possivel, senão juntá-las a esmo, ainda que o muito que merece a Escola exigisse mais.

Não teria escusas se as procurasse na exiguidade de tempo, afeto a outras atividades. Pois, ainda que não esteja preso ao regime do tempo integral, não parece que possa o professor escusar-se ao cabal desempenho de suas funções, com o desempenho de outros encargos.

Mas é que não dista de mais de uma semana a data em que assumi a cátedra, de sorte que dista menos de uma semana o vínculo que me impôs fazer a aula inaugural dêste ano dos cursos jurídicos.

Que a Escola possa orgulhar-se dêsses cursos no presente ano. Que possam os alunos tirar deles o máximo proveito, o maior estímulo, o impulso na boa direção, que tenham a tomar depois, na vida. Que os levem regularmente, sem interrupções, sem decretos de aprovação, para que sempre digam, orgulhosamente, com orgulho verdadeiro, que a filiação moral e intelectual de suas doutrinas e conhecimentos deriva da Faculdade de Direito, da terra de São Paulo. 